\title{
Experiences of pregnancy and motherhood among teenage mothers in a suburb of Accra, Ghana: a qualitative study
}

This article was published in the following Dove Press journal:

International Journal of Women's Health

II November 2013

Number of times this article has been viewed

\author{
Nana Yaa Konadu Gyesaw' \\ Augustine Ankomah ${ }^{2}$ \\ 'Regional Health Directorate, Ghana \\ Health Service, Koforidua, Eastern \\ Region, ${ }^{2}$ Department of Population, \\ Family and Reproductive Health, \\ School of Public Health, University \\ of Ghana, Accra, Ghana
}

Background: The proportion of teenage girls who are mothers or who are currently pregnant in sub-Saharan African countries is staggering. There are many studies regarding teenage pregnancy, unsafe abortions, and family planning among teenagers, but very little is known about what happens after pregnancy, ie, the experience of teenage motherhood. Several studies in Ghana have identified the determinants of early sexual activity, contraception, and unsafe abortion, with teenage motherhood only mentioned in passing. Few studies have explored the experiences of adolescent mothers in detail with regard to their pregnancy and childbirth. This qualitative study explores the experiences of adolescent mothers during pregnancy, childbirth, and care of their newborns.

Methods: This qualitative study was based on data from focus group discussions and indepth interviews with teenage mothers in a suburb in Accra. Participants were recruited from health facilities as well as by snowball sampling.

Results: Some of the participants became pregnant as a result of transactional sex in order to meet their basic needs, while others became pregnant as a result of sexual violence and exploitation. A few others wanted to become pregnant to command respect from people in society. In nearly all cases, parents and guardians of the adolescent mothers were upset in the initial stages when they heard the news of the pregnancy. One key finding, quite different from in other societies, was how often teenage pregnancies are eventually accepted, by both the young women and their families. Also observed was a rarity of willingness to resort to induced abortion.

Conclusion: Special programs should be initiated by the government and the various responsible departments to address ignorance on sexual matters, and the challenges and risks associated with pregnancy and parenting by adolescents. Parenting techniques should be taught in sex education programs

Keywords: teenage pregnancy, teenage motherhood, adolescents, unmarried teenagers, focus group discussions, Ghana

\section{Introduction}

Approximately 16 million teenage girls become mothers every year, ${ }^{1}$ but the highest concentration is in sub-Saharan Africa, where $20 \%-40 \%$ of teenagers are mothers or currently pregnant. ${ }^{2}$ Pregnancy and childbirth are the leading causes of death among adolescents in sub-Saharan Africa. ${ }^{2}$ Adolescent motherhood requires support and community involvement, regardless of the mother's age and socioeconomic position. ${ }^{3-5}$ A systematic review of the literature has revealed that adolescent mothers tend to be poor and care for their children in impoverished circumstances that are hard to either escape from or improve. ${ }^{6}$ Teenage mothers and their children are at risk of long-term disadvantages due to lack of preparation and the maturity needed to be a parent. ${ }^{3,7}$
Correspondence: Augustine Ankomah Department of Population, Family and Reproductive Health, School of Public Health, University of Ghana, PO Box LGI3, Legon, Accra, Ghana Email augankomah@gmail.com 
Repeat pregnancies and subsequent childbirths are also likely to occur. ${ }^{8,9}$

It is universally known that neonatal mortality increases as the age of the mother decreases; teenagers who give birth before the age of 15 years are five times more likely to die during pregnancy or delivery as women in their 20s, partly as a result of physical immaturity. ${ }^{10}$ Older adolescents are twice as likely to die during pregnancy and delivery. ${ }^{11}$ In sub-Saharan Africa, adolescent mothers are significantly disadvantaged and face tremendous challenges during pregnancy and early motherhood. Adolescent mothers have higher complication rates during both pregnancy and delivery. Compared with adult mothers, adolescent mothers are at increased risk of experiencing poor maternal and infant outcomes, such as maternal and infant death or having a low birth weight infant. ${ }^{12}$ A report on adolescent fertility points out that the number of births to adolescents in subSaharan Africa is projected to increase over the next few decades, exceeding a total of 4.8 million births to girls aged 15-19 years during the period from 1995 to $2020 .{ }^{13}$ A study in Swaziland indicated that adolescent mothers experienced problems in several aspects of their lives. The most pressing problems were lack of support from individuals and institutions, including educational, social, cultural, and financial problems. ${ }^{14}$

Ghana has one of the highest child marriage prevalence rates in the world. Twelve percent of girls aged 15-19 years are either pregnant or have already given birth. ${ }^{15}$ The adolescent birth rate in Ghana in 2011 was 60 per 1,000 women. ${ }^{15}$ In one district, Gomoa West (of over 270 districts in Ghana), a total of 762 teenagers became pregnant in 2012, some of whom were aged between 10 and 14 years. ${ }^{16}$ Other districts have reported high pregnancy rates, including Builsa District in the Upper East Region of Ghana ${ }^{17}$ and Wasa Amenfi in the Western Region. ${ }^{18}$

In Ghana, adolescent childbearing has potentially negative demographic and social consequences, and births to teenage mothers have been found to have the highest infant and child mortality. ${ }^{19,20}$ A study in a small rural town in Ghana revealed that $19 \%$ of junior high students had already given birth. ${ }^{21}$

Much attention is paid to teen pregnancy, unsafe abortions, and contraceptive use among teenagers. Consequently, several studies done in Ghana have identified the correlates and determinants of early sexual activity, pregnancy, contraception, and unsafe abortions. ${ }^{20,22}$ However, only a few have explored the experiences of adolescent mothers. ${ }^{23,24}$ The main objective of this paper, therefore, is to use qualitative data to explore the experiences of unmarried teenage mothers in relation to pregnancy, delivery, and early motherhood.

\section{Materials and methods}

This was a qualitative study based on focus group discussions and indepth interviews among teenage mothers.

\section{Study setting}

The study was conducted in Ga East Municipality, a suburb of Accra, Ghana's capital city. The municipality, which consists of four submunicipalities, ie, Madina, Danfa, Taifa, and Dome, is a relatively poor community. Although a few inhabitants are employed in the public service, petty trading and small-scale farming are the dominant occupations. A sizeable portion of the labor force in the municipality is unemployed, a fact reflected in the high poverty level. The community is made up of two main religions, Christianity and Islam, with two dominant ethnic groups, Akan and Ga.

\section{Sampling and recruitment of study participants}

The data for the study were derived from eight focus group discussions, which were held in April and May of 2012, with a total of 54 teenage mothers aged 14-19 years living alone or with their parents or guardians. To ensure ethnic and religious variations of participants, two focus groups were held in each of the four submunicipalities. Indepth interviews were also held with nine teenage mothers.

\section{Recruitment process}

Recruitment occurred at both the facility and community levels. At the facility level, a nurse volunteer compiled a list of all teenage mothers who had recently visited the facility. From the list, some mothers were traced who, in turn, through snowball sampling, led us to other teenage mothers. For each person listed and contacted, the nurse volunteer or the female co-author explained to the teenage mother the nature of the research and sought their voluntary participation. The community recruitment was done through appropriate community gatekeepers or "mobilizers". With their substantial local knowledge of the community, and based on the briefing of the researchers, the community mobilizers identified houses where potential study participants resided. To ensure that the study included teenage mothers who may not have attended health facilities, the facilitators were specifically tasked to identify such teenage mothers. Again, a snowball approach was employed to expand the list of potential participants. 
The identified study participants were visited at home by the female co-author. A brief explanation of the study objectives was given to both parents and other adult guardians. The home visits were done to help establish rapport and build confidence among parents, guardians, and the investigator. During the home visits, dates and venues for focus groups and indepth interviews were also discussed. Upon arriving at a consensus, telephone calls were made to each of the participants to confirm the time, place, and date for the discussion or interview.

\section{Structure of focus group discussions}

The focus group discussions were moderated by the female co-author, who has a nursing background and is experienced in interacting with adolescents. There was also a male notetaker who, among other things, captured nonverbal responses, cues, and other interactions. Each focus group discussion was made up of 6-9 participants. Discussions normally lasted for about an hour. The focus group discussions were held in venues that were convenient for participants, such as open spaces at the health facility (after close of clinic hours) and community centers. All discussions were held in one of the two predominant languages in the municipality, namely Ga or Twi. Snacks were provided, but no financial or other incentives were offered to participants except for reimbursement of transportation costs. With the consent of participants, the focus group discussions were audio-recorded.

\section{Topics}

A focus group discussion guide was developed to facilitate the discussion. The topics discussed included the circumstances leading to the participants' pregnancies and reactions from parents and partners, as well as experiences with labor and the early phases of motherhood.

\section{Indepth interviews}

With regard to the indepth interviews, six respondents were recruited from the health facility during special clinic days set aside for mothers, while three respondents were recruited from the community to reflect mothers who do not have access to health facilities. An interview guide, based on topics similar to the focus group discussions, was used to conduct the indepth interviews.

\section{Ethical considerations}

Written informed consent and verbal consent were sought and obtained from all participants. Permission was also obtained from parents and guardians. Participants were assured of confidentiality. Ethical approval for the study was given by the Ghana Health Service ethical review board.

\section{Analysis}

After every focus group discussion and indepth interview, the recorded discussions were fully transcribed and translated verbatim into English. Coding was done manually based on key words and phrases developed from the data. The codes were then "grouped together under higher order headings". ${ }^{25}$ Consequently, on a higher logical level of abstraction, codes, subcategories, categories, and themes were created. These themes were categorized according to experiences in relation to pregnancy, childbearing and childcare, and parental views and reactions. The researchers then sorted the data thematically by clustering together material with similar content. At this stage, the researcher employed creative and analytical reasoning to determine categories of meaning. ${ }^{26}$

Qualitative analysis may focus on manifest or latent content, or a combination of both. ${ }^{27}$ Manifest analysis describes the visible and the obvious, while latent content analysis involves an interpretation of the underlying and inferred meaning of the text. ${ }^{27,28}$ Latent analysis, among others, allows for indepth interpretation and systematic and thorough evaluation to assess the presence or absence of a particular idea or theory. ${ }^{27,28}$ The research team met on various occasions to discuss the coding, analysis, and interpretation, as well as to address discrepancies that required clarification. Representative quotes that best described the categories were agreed upon by the authors and selected, but in some instances, contrasting minority opinions were also highlighted.

\section{Results Characteristics of participants}

Fifty four respondents participated in the eight focus group discussions while nine respondents participated in the indepth interviews. The participants in the study were teenage mothers aged 14-19 years. There was a mixture of participants who understood and spoke both Ga and Twi and a mixture of Christians and Muslims. In terms of parity, the participants were all mothers of at least one child. Some basic characteristics of the focus group participants are presented in Table 1. The educational background of the participants of the study included primary, junior high school, and vocational education. Of the 54 participants, many were apprentices learning vocational trades, a few had returned to school after delivery, and the majority were not engaged in any employment. 
Table I Characteristics of participants

\begin{tabular}{|c|c|c|c|c|}
\hline Community & FDG & Participants & $\begin{array}{l}\text { Educational } \\
\text { level }\end{array}$ & Occupation \\
\hline Danfa & I & 9 & Primary, JHS & $\begin{array}{l}\text { School, } \\
\text { unemployed }\end{array}$ \\
\hline Madina & 2 & 7,6 & Primary, JHS & $\begin{array}{l}\text { Unemployed, } \\
\text { apprenticeship }\end{array}$ \\
\hline Dome & I & 8 & JHS & $\begin{array}{l}\text { Unemployed, } \\
\text { apprenticeship }\end{array}$ \\
\hline Taifa & 2 & 6,6 & $\mathrm{JHS}$ & Unemployed \\
\hline Abokobi & I & 6 & JHS, vocational & Unemployed \\
\hline Pantang & I & 6 & JHS, vocational & Unemployed \\
\hline
\end{tabular}

Abbreviations: JHS, junior high school; FDG, focus group discussion.

\section{Reasons for becoming pregnant}

Transactional sex

For about half of the young mothers, the sexual encounters that resulted in their pregnancy were the result of transactional sex. Many narrated the financial challenges they faced and how they felt they could exchange sex for material gains; many of their parents and other relatives could not or would not provide the basic needs of the teenagers.

"I was in school and I had to pay my exam fees .... I needed money. Then this boy expressed interest in me. He helped me on more than two occasions, which landed me with a pregnancy." (17 years old).

"I was in school and my mother said she had no money for me. The man said he would take care of me, but then there was a pregnancy, then a child, and then this second pregnancy." (17 years old).

"He lured me into getting pregnant. He conned me with sweet talk and gifts." (15 years old).

A few of the girls mentioned that their mothers were wealthy but refused to provide them with basic needs. This compelled some to engage in transactional sex:

"My mother has money but she does not give me any, not even basic needs for a normal girl. Then I went to watch television and met my boyfriend who promised to look after me ... then I became pregnant." (18 years old).

\section{Sexual violence and abuse}

About two of every ten participants reported being sexually abused or exploited by people in authority. Among such cases were teachers who took advantage of their roles and positions and coerced the adolescent to have sex, which resulted in pregnancy.

"I was impregnated by my class teacher who was fond of me. I used to go to do chores for him. He took advantage of me and put me in the family way." (18 years old).
A few participants (about five) reported that their pregnancies resulted from rape, often committed by acquaintances.

"I was walking and the boy, who lives near our house, he raped me. He was arrested by the police and punished (kept in cell) for two weeks. But later he was freed." (14 years old).

\section{Adolescent sexual experimentation}

A few of the participants accepted responsibility and admitted that they became "too difficult" for their mothers to control. They went their own way to experiment by engaging in sex. They felt it was a stage in the life of an adolescent, a period where most adolescents turn rebellious and do not listen to counsel. They preferred to explore and take advice from peers and not from parents. These mothers emphasized that even where parents may be providing for all their needs, sheer stubbornness led them into pregnancy.

"I was very stubborn. I had no financial problems. I created that problem. I could have turned down the boy's proposal, but I did not. He became my boyfriend and made me pregnant." (19 years old).

\section{Lack of sex education}

In each discussion group, there were young adolescents who mentioned that they were naïve and did not know anything about the implications of sexual intercourse; they did not know they could become pregnant.

"We were both young and had just started a relationship; we did not know anything. We were experimenting, which resulted in the pregnancy." (16 years old).

\section{"I wanted to be a teenage mum!"}

A few of the adolescents mentioned that they chose to become pregnant, and that they had always wanted to have children early in life. They explained that they wanted to "prove they were mature" and felt pregnancy enhanced their societal value, because it is socially demanded that pregnant women be respected. Some of the participants who became pregnant in late adolescence appreciated this viewpoint. They mentioned that they were older, mature, and were very much involved.

"My boyfriend made me pregnant. I was aware of everything. I was aware of it. I just wanted it. I am ready." (19 years old).

The reasons given for pregnancy are summarized in Table 2 . 
Table 2 Reasons for pregnancy

\begin{tabular}{|c|c|}
\hline Transactional sex & $\begin{array}{l}\text { Sex in exchange for monetary and other benefits } \\
\text { due to financial needs that could not or would not } \\
\text { be met by their families }\end{array}$ \\
\hline $\begin{array}{l}\text { Sexual violence } \\
\text { and abuse }\end{array}$ & $\begin{array}{l}\text { Forced sex including coercion from people they } \\
\text { knew to be friends or acquaintances, outright rape }\end{array}$ \\
\hline $\begin{array}{l}\text { Adolescent sexual } \\
\text { experimentation }\end{array}$ & $\begin{array}{l}\text { Characteristic refusal of adolescents to be } \\
\text { controlled, rebellion, and youthful curiosity about } \\
\text { sexual intercourse leading to sexual experimentation }\end{array}$ \\
\hline $\begin{array}{l}\text { Lack of sex } \\
\text { education }\end{array}$ & $\begin{array}{l}\text { Naiveté and a general lack of knowledge about } \\
\text { protected sexual intercourse and its implications }\end{array}$ \\
\hline $\begin{array}{l}\text { "I wanted to be a } \\
\text { teenage mum!" }\end{array}$ & $\begin{array}{l}\text { An assumption of readiness and belief that having } \\
\text { children is a requirement for societal respect }\end{array}$ \\
\hline
\end{tabular}

\section{"I am pregnant!"}

The majority of the participants did not know they were pregnant and did not expect pregnancy. A few of them were still menstruating during the first trimester. It was their parents and guardians who first noticed the pregnancy.

"I was not expecting anything. I didn't know I was pregnant. It was my mother who realized I was pregnant because I was vomiting all the time but still menstruating." (16 years old).

"I didn't know, but when I realized it, it was very late. It was 6 months old and I was still menstruating." (17 years old).

"I started vomiting and spitting, then I realized something was inside." (19 years old).

I was living with my aunty, who realized that my attitude towards the usual household chores had changed. It wasn't until two months later when my menses wasn't coming that I accepted I was pregnant.” (16 years old).

Many of the participants, however, knew they were pregnant very early in the pregnancy. Most knew they were pregnant after missing their menstrual periods.

"When the month came for me to have my menses, it did not come and when the time elapsed for about two days, I went to get a pregnancy test. The result came out positive." (19 years old).

(Laughing) "When I was to have my menses that month, it did not come and I knew what was wrong." (17 years old).

\section{Reaction from parents}

The greatest fear of most of the participants was that of how their parents would react upon hearing about the pregnancy. The majority of respondents indicated their parents or guardians were not happy on learning that they were pregnant. To many parents, the pregnancies came as a surprise. Parental reaction varied. Nearly all parents were upset and some were shocked.

"I was living with my mother before the pregnancy and she really reprimanded me for getting pregnant. Mother was really upset and depressed. She fumed at me, 'I have spent millions on your education and now this has happened'.,

A few mentioned that reactions from fathers were much more intense and difficult to handle. While the reactions of mothers were sharp, immediate, and often vocal, the fathers were deeply troubled, intensely moody, and felt deeply hurt.

“My dad was very angry. He didn't talk to me for about three months. My mother had to go talk to him on my behalf before he forgave me." (18 years old).

The young mothers explained that parents reacted in the way they did out of love for the children. Many parents were concerned that they would not be able to continue their education.

"My parents were very upset with me because they thought with the pregnancy that I would not go back to school." (17 years old).

In rare situations, mothers had no problem accepting the pregnancy.

"My mother had no problem as she needed grandchildren.

She had no problem at all." (19 years old).

\section{Partner's reaction}

Most of the participants mentioned the reactions of their partners when they told them of the pregnancies were positive.

"My partner was calm with the news. He said he was going to inform his family. Later, my Dad sent a delegation to his people. They readily accepted [the pregnancy]." (19 years old).

In a few instances, the partners were excited about the pregnancy because it would make the girl accept their proposal of marriage.

"My partner wanted to marry me but I had been preventing him because I wanted to complete my apprenticeship. This made it easy for him." (18 years old).

In a few cases, however, partners flatly denied they were responsible for the pregnancy.

"He denied responsibility for the pregnancy." (15 years old). 


\section{Option of abortion}

More than half of the participants noted that abortion was discussed as a way out. While nearly all parents advised the teenagers not to consider abortion, others mentioned parents who wanted to facilitate abortion.

"My mother warned me not to abort, that she would support me until I delivered." (16 years old).

"My parents wanted me to abort the pregnancy, but when we went to check the gestation of the pregnancy, it was too old for an abortion." (16 years old).

Many reported that while their partners were against abortion for fear of complications that might lead to death, a few others tried unsuccessfully to abort the pregnancy.

"My partner was strongly against abortion. He told me that, where he comes from, it is a taboo to commit abortion and whoever tries it dies." (18 years old).

"I told my partner and he asked me what I wanted to do. He brought me some medicine for an abortion, but the pregnancy wouldn't abort. He even went to the extent of giving me akpeteshie (local gin), but still no abortion." (19 years old).

\section{Teenagers in labor}

The study asked participants to recall their experiences during labor. Almost all the participants testified to the pain that came with labor.

"I toiled so much during labor. So when I delivered, I said, 'Oh thank God'." (19 years old).

"Labor was difficult and painful. I kept crawling on the floor. Whoever says that labor is easy is lying." (18 years old).

"I went to the health center when I started having severe stomach pain. I was then referred to the district hospital." (16 years old).

"I had a stomach upset ... it was labor. I had to walk for about 3 miles to the health center. It was a good decision, as my mother had gone to work. Five minutes after getting there, I delivered. The least bit of delay and I would have delivered on the way." (18 years old).

\section{First sight of the baby}

Most of the participants had no regrets about carrying the pregnancy to term. Upon seeing the newborn for the first time, nearly all participants mentioned that the pain and suffering vanished.
"After delivery when my son was handed over to me, I looked into his face. I remembered the suffering and said "Wow! I won't give birth again." I was teased until I left the health facility." (18 years old).

"I had no regrets about carrying the pregnancy to term. I was very glad to have had the baby. Even sometimes when I am at home and I look at my baby, I become so happy because there are people out there, who have money, who want what I have but cannot." (19 years old).

"I had no regrets for having the baby .... so relieved. The baby was shown to me; I was alive to see my child.' (16 years old).

There was no regret about having the child, but the pain of interruption in education was notable for some of the mothers.

"I was hurt with regard to my education. I was so glad when I saw my baby. I had no regrets ... no one can tell what the child will do for me in the future." (18 years old).

\section{Caring for the baby}

Regarding the level of care the adolescent mothers gave to their newborns, nearly all the adolescents had some assistance from their family in caring for their child. In nearly all cases, the young mothers were supported by their mothers or other older family members. Many admitted that because they lacked parental skills, they could not have coped on their own.

"My mother took the child from me so I could go back to school. With regards to caring for the child, it's my mother's duty." (14 years old).

"I was not feeling well after delivery so it was my mother who did everything for us. She only brought her to me to suckle." (18 years old).

"My aunty has been so good to my child and myself. She bought the baby's clothes and all that the baby needed, she got them." (16 years old).

A few of the participants mentioned that their partners showed so much love, attention, and support towards the caring of their child. They discharged their duties and responsibilities towards the care of the child.

"I had no problem at all. My boyfriend provided for all our needs and my mother also helped in caring for the baby." (16 years old)

"My partner was and continues to be supportive in the care of the child." (19 years old) 
While the majority of mothers had help from family and partners in caring for the newborn, others had no such help. This caused some regret and pain.

"I regretted not aborting the pregnancy because I was not working and my man was not supporting us either." (19 years old).

\section{Discussion}

The findings show that adolescent mothers face numerous challenges that place demands not only on the young mother's stage of adolescent development, but also on their ability to adapt to the obligations of parenthood. As noted in the literature, teenage mothers are faced with meeting the needs of their infant as well as seeking ways to satisfy their own needs as adolescents. They also need support from peers who understand and can identify with their new role as a parent; this provides them with a sense of acceptance, socialization, and stability. ${ }^{29}$

Confirming studies elsewhere, many of the teenage mothers mentioned that caring for their newborns was the most challenging responsibility they have ever faced. ${ }^{30} \mathrm{~A}$ study in Swaziland reported similar challenges experienced by adolescent mothers. ${ }^{14}$ Similar findings have been reported from South Africa. ${ }^{13}$ Some authors suggest that adolescent mothers are stigmatized by the community and are likely to experience violence from parents and rejection by partners., ${ }^{2,14}$ On the whole, this assertion was not supported in this study. Although there were examples of parents and families reacting negatively to the pregnancy of a teenage relative, particularly at the stage of hearing of the pregnancy, there was a relatively tolerant acceptance of the pregnancy. This confirms similar findings from a study almost two decades ago in another Ghanaian community where mothers were disappointed that their daughters could not exercise restraint, but welcomed the pregnancies. ${ }^{23}$ Most families embarked upon flexible arrangements to care for and deal with both the needs of the mother and newborn baby.

The culpability of male adults in teenage pregnancies through sexual coercion was noted. A few became pregnant through rape. Aside from those who became pregnant in circumstances beyond their control, there were those who consented to becoming pregnant to earn respect from their communities. They wanted to prove to society that they were older and mature and should be accorded the respect given to mothers. It is often assumed that early childbearing is always unintentional, but in this study, as in other similar research, some adolescents do plan their pregnancy and seek motherhood to gain adult status and a sense of fulfilment. ${ }^{3,31}$

Despite the physiologic immaturity of the girls, they managed to carry their pregnancies to term and did not resort to abortion. The only regret expressed by some was the fact that there would be an interruption or a complete halt in their education. The majority of the teenage mothers had their partners and families assisting them financially. A few of the mothers, however, had no one to help them and had to manage on their own with their child. Many of the teenage mothers, as confirmed in an earlier study, ${ }^{32,33}$ were concerned about dropping out of school and cared very much about returning to school and achieving their educational aspirations and earning a living.

Although this research provides data for understanding the experiences, challenges, and coping mechanisms of teenage mothers, it is a qualitative study with potential biases resulting from selection issues, so its results are not representative and therefore not generalizable for all teenage mothers in Ghana. Further, qualitative data could be subject to multiple interpretations.

\section{Conclusion}

Adolescent mothers face numerous challenges that put demands not only on the young mother's stage of adolescent development but also on their ability to adapt to the obligations of parenthood. Adolescent mothers go through a variety of experiences in pregnancy, including financial hardship. One key finding is evidence of how often teenage pregnancies are eventually accepted by both the young women and their families, despite early displeasure at receiving the news. Also observed was a rarity of willingness to resort to induced abortion.

This study identified several challenges faced by teenage mothers. Solutions to the holistic problems of the adolescent mother cannot be found in the activities of a single individual or service. The solutions can only be found through the coordinated effort of a multidisciplinary and intersectoral team. The role of school health nurses should be expanded to providing information on pregnancy and its risks, contraceptive use, abortion and its complications, and early childbirth and its consequences. There is also a need for health educators to focus on local high-risk groups and high-risk behavior. In addition, teenagers should be taught assertive interpersonal skills development, such as negotiating and refusal skills in programs that allow young people to practice these skills. Special programs should be initiated 
by government and the various responsible departments to address ignorance concerning sexual matters, and the challenges and risks associated with pregnancy and parenting by adolescents. Parenting techniques should be taught in sex education programs.

\section{Disclosure}

The authors report no conflicts of interest in this work.

\section{References}

1. World Health Organization. Media Centre. 2009. Available from: http:// www.who.int. Accessed October 21, 2011.

2. Atuyambe L, Mirembe F, Tumwesigye N, Annika J, Kirumira E, Faxelid E. Adolescent and adult first time mothers' health seeking practices during pregnancy and early motherhood in Wakiso District, Central Uganda. Reprod Health. 2008;5:13.

3. Hanna B. Negotiating motherhood: the struggles of teenage mothers. J Adv Nurs. 2000;34:456-464.

4. Breheny M, Stephens C. Individual responsibility and social constraint: the construction of adolescent motherhood in social scientific research. Cult Health Sex. 2007;9:333-346.

5. Meadows-Oliver M. Adolescent mothers' experiences of caring for their children while homeless. J Pediatr Nurs. 2009;24:458-467.

6. McDermott E, Graham H, Hamilton V. Experiences of being a Teenage Mother in the UK: A Report of a Systematic Review of Qualitative Studies. Lancaster, UK: Lancaster University; 2004.

7. Singh S. Adolescent childbearing in developing countries: a global review. Stud Fam Plann. 1998;29:117-136.

8. Chase-Lansdale L, Brooks-Gunn J, Paikoff RL. Adolescent mothers: missing links and future promises. Fam Relat. 1991;40:396-403.

9. Aujoulat I, Libion F, Berrewaerts J, Noirhomme-Renard F, Deccache A. Adolescent mothers' perspectives regarding their own psychosocial and health needs: a qualitative exploratory study in Belgium. Patient Educ Couns. 2010;81:448-453.

10. World Health Organization. Fact sheet: Why is giving special attention to adolescents important for achieving Millennium Development Goal Five? 2008. Available from: http://www.who.int/making_pregnancy_ safer/events/2008/mdg5/adolescent_preg.pdf. Accessed October 8, 2013.

11. United Nations Population Fund. Giving Girls Today and Tomorrow: breaking the cycle of adolescent pregnancy. 2007. Available from: http://www.unfpa.org/webdav/site/global/shared/documents/ publications/2007/giving_girls.pdf. Accessed October 8, 2013.

12. Westoff CF. Trends in Marriage and Early Child Bearing in Developing Countries. Calverton, MD: ORC Macro; 2003.

13. Kaufman C, De Wet T, Stadler J. Adolescent Pregnancy and Parenthood in South Africa. New York, NY: Population Council Inc; 2000.

14. Dlamini LS. The problems of teenage mothers in the southern HHOHHO region of Swaziland. MSc Thesis, University of South Africa, Advanced Nursing Sciences Department; 2002.
15. Ghana Statistical Service. Ghana Multiple Indicator Cluster Survey with Enhanced Malaria Module and Biomarker, 2011, Final Report. Accra, Ghana: Ghana Statistical Service; 2012.

16. GhanaWeb. 750,000 teenagers become pregnant in Ghana annually. Accra, Ghana: Ghana News Agency; 2013. Available from: http:// www.ghanaweb.com/GhanaHomePage/News Archive/artikel. php?ID=273590. Accessed October 8, 2013.

17. Aboalik $\mathrm{G}$. The impact of teenage pregnancy on the education of girls in the Builsa District of Ghana. Bachelor's dissertation. Winneba, Ghana: University of Education; 2004.

18. Adesoka J, Moses SA, Quagraine L, Siaw L. Incidence, causes and effects of teenage pregnancy among public JHS Girls in the WASSA Amenfi District in the Western Region of Ghana. Undergraduate research project. Cape Coast, Ghana: University of Cape Coast; 2008.

19. Ghana Statistical Service. Ghana Demographic and Heath Survey 2008. Accra, Ghana: GSS, GHS, and ICF Macro; 2009.

20. Awusabo-Asare K, Abane A, Kumi-Kyereme A. Adolescent Sexual and Reproductive Health in Ghana: A Synthesis of Research Evidence. Occasional Report No 13. New York, NY: The Alan Guttmacher Institute; 2004.

21. Afenyadu D, Goparaju L. Adolescent Sexual and Reproductive Health Behaviour in Dodowa, Ghana. Washington, DC: CEDPA; 2003.

22. Agyei WKA, Biritwum RB, Ashitey AG, Hill RB. Sexual behaviour and contraception among unmarried adolescents and young adults in Greater Accra and Eastern Regions of Ghana. J Biosoc Sci. 2000;32:495-512.

23. Keller ET, Hilton DB, Twumasi-Ankrah K. Teenage pregnancy and motherhood in a Ghanaian community. J Soc Dev Afr. 1999;14: 69-84.

24. Henry R, Fayorsey C. Coping with Pregnancy: Experiences of Adolescents in Ga Mashi, Accra. Calverton, MD: ORC Macro; 2004.

25. Burnard P. A method of analyzing interview transcripts in qualitative research. Nurse Educ Today. 1991;11:461-466.

26. Welman JC, Kruger SJ, Mitchell B. Research Methodology. Cape Town, South Africa: Oxford University Press; 2002.

27. Graneheim UH, Lundman B. Qualitative content analysis in nursing research: concepts, procedures and measures to achieve trustworthiness. Nurse Educ Today. 2004;24:105-112.

28. Kondracki NL, Wellman NS, Amundson DR. Content analysis: review of methods and their applications in nutrition education. J Nutr Educ Behav. 2002;34:224-230.

29. DeVito J. How adolescent mothers feel about becoming a parent. J Perinat Educ. 2010;19:25-34.

30. Nystrom K, Ohrling K. Parenthood experiences during the child's first year: literature review. J Adv Nurs. 2004;46:319-330.

31. Clemmens D. Adolescent motherhood: a meta-synthesis of qualitative studies. MCN Am J Matern Child Nurs. 2003;28:93-99.

32. Kumi-Kyereme A, Awusabo-Asare K, Biddlecom A, Tanle A. Influence of social connectedness, communication and monitoring on adolescent sexual activity in Ghana. Afr J Reprod Health. 2007;11:133-136.

33. Kumi-Kyerme A, Biddlecom AE, Awusabo-Asare K. Adolescents' Sexual and Reproductive Health: Qualitative Evidence from Ghana. Occasional Report, No 30. New York, NY: The Alan Guttmacher Institute; 2007.
International Journal of Women's Health

\section{Publish your work in this journal}

The International Journal of Women's Health is an international, peerreviewed open-access journal publishing original research, reports, editorials, reviews and commentaries on all aspects of women's healthcare including gynecology, obstetrics, and breast cancer. The manuscript management system is completely online and includes

\section{Dovepress}

a very quick and fair peer-review system, which is all easy to use. Visit http://www.dovepress.com/testimonials.php to read real quotes from published authors. 